\title{
Hepatocellular Small Cell Change
}

National Cancer Institute

\section{Source}

National Cancer Institute. Hepatocellular Small Cell Change. NCI Thesaurus. Code C96765.

A premalignant neoplastic lesion of the liver. It is characterized by the presence of hepatocytes with decreased cell volume, increased nuclear/cytoplasmic ratio, basophilia, mild nuclear pleomorphism, and hyperchromasia. 